克楼日五十二月一十年二十二治明

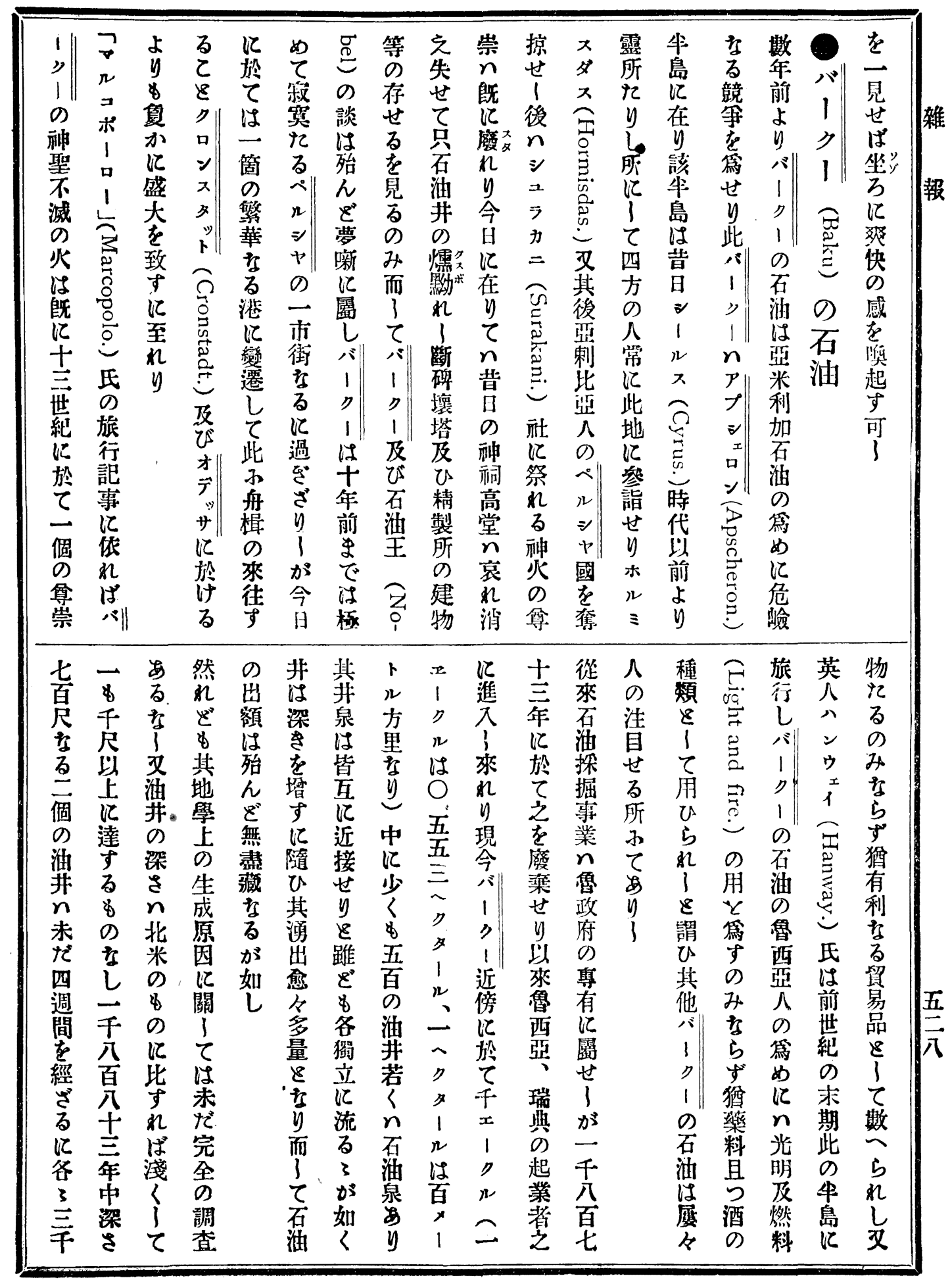




\section{卷一十第集一第誌雑 悬地}

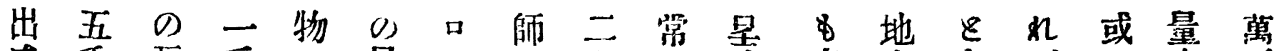

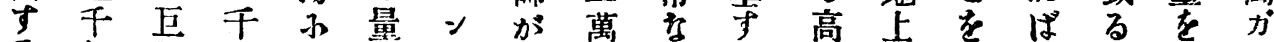

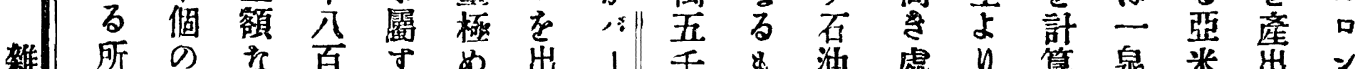

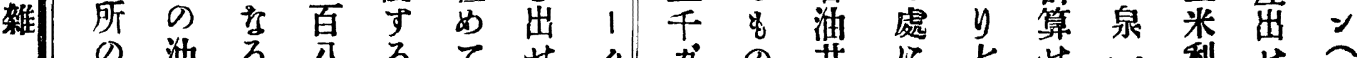

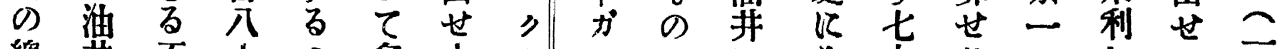

總据石士心

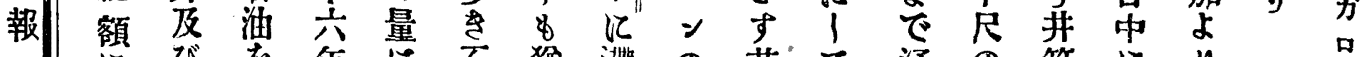

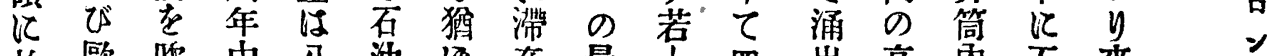

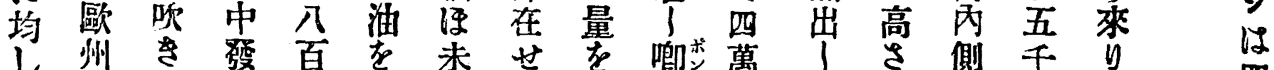

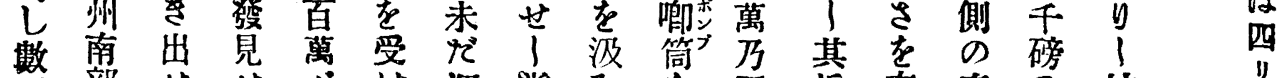

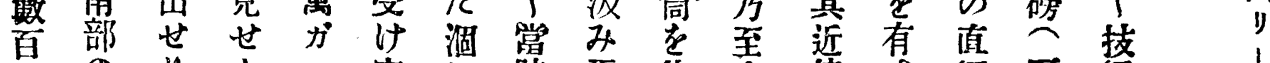

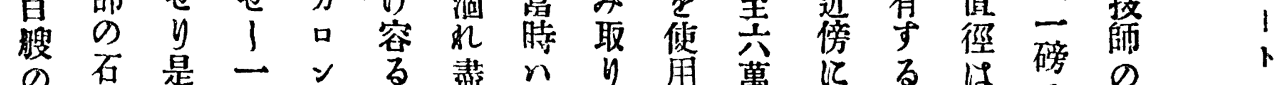

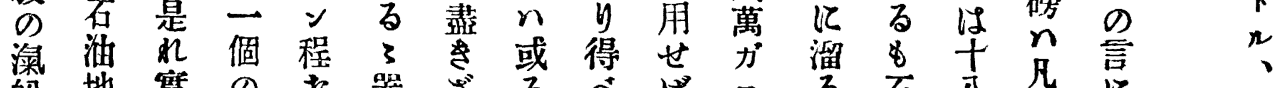

船方䆥

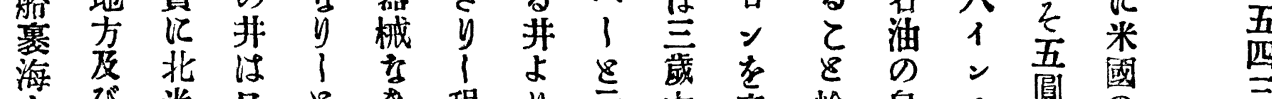

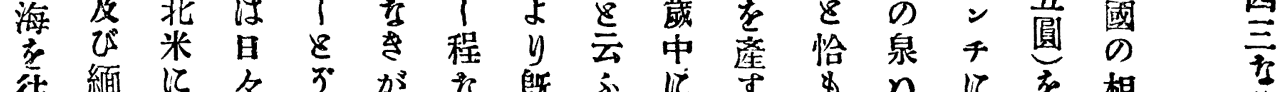

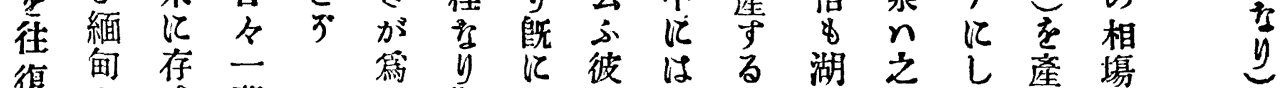

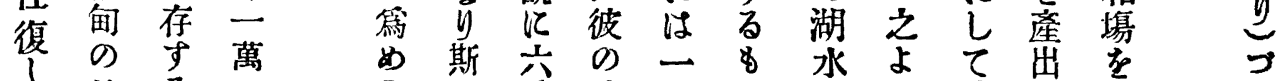

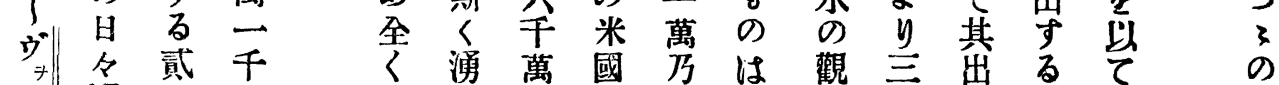

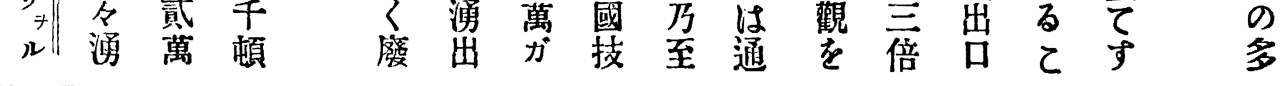

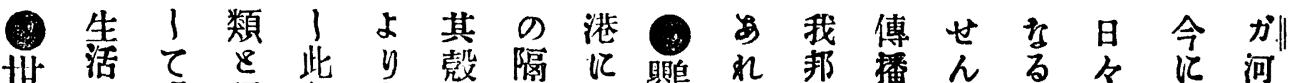

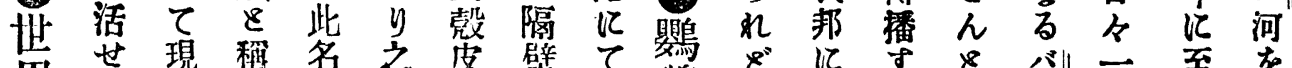
界 $y$ 時 す 名老皮壁て獲鵡

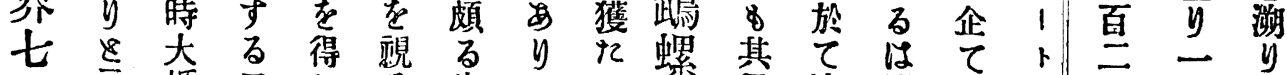

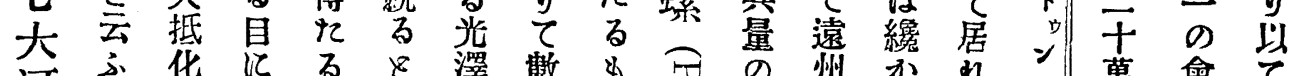

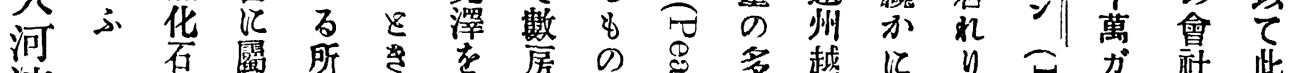

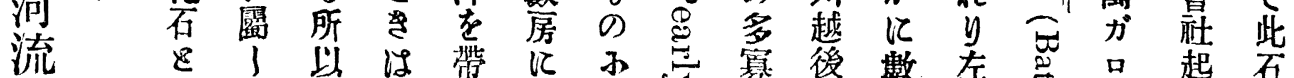

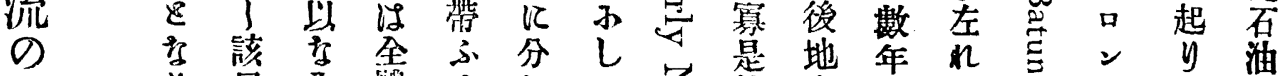

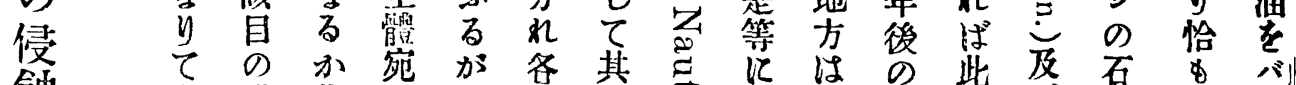

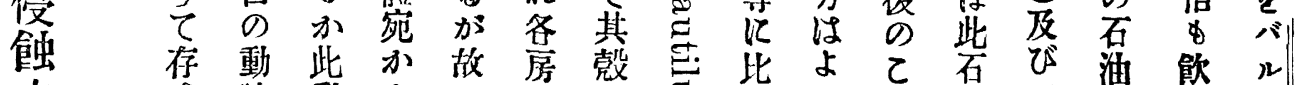

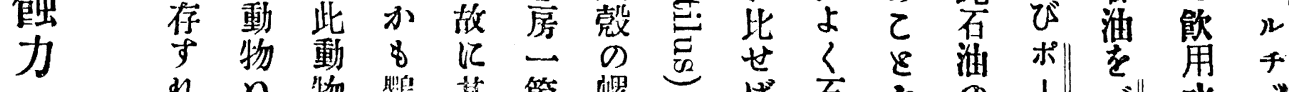

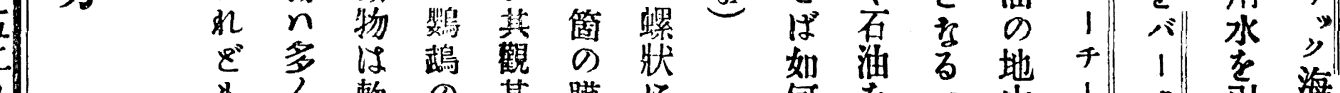

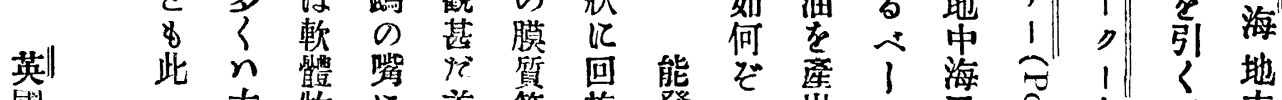

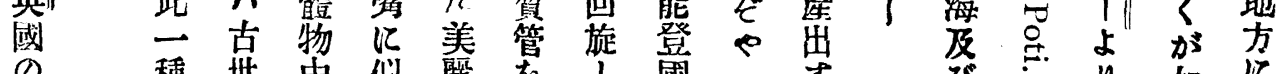

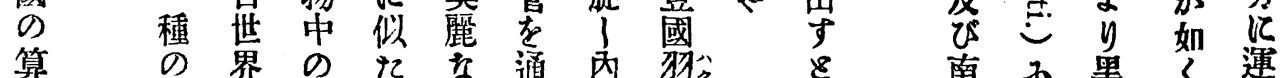
算 の 界の 家 今 8 鰓 是

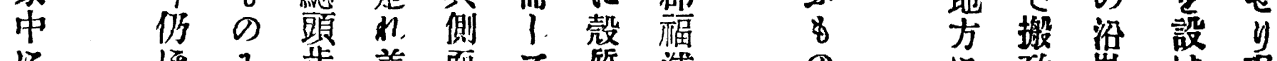

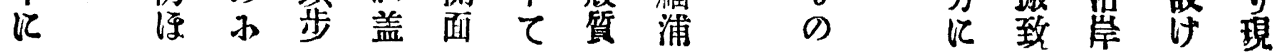

